\title{
Photothermal ablation of pancreatic cancer cells with hybrid iron-oxide core gold-shell nanoparticles
}

This article was published in the following Dove Press journal:

International Journal of Nanomedicine

5 September 2013

Number of times this article has been viewed

\author{
Yang Guo' \\ Zhuoli Zhang' \\ Dong-Hyun Kim ${ }^{1,5}$ \\ Weiguo $\mathrm{Li}^{\prime}$ \\ Jodi Nicolai' \\ Daniel Procissi' \\ Yi Huan ${ }^{2}$ \\ Guohong $\mathrm{Han}^{3}$ \\ Reed A Omary ${ }^{1,4,5}$ \\ Andrew C Larson 1,4,5 \\ 'Department of Radiology, \\ Northwestern University, Chicago, IL, \\ USA; ${ }^{2}$ Department of Radiology, \\ Xijing Hospital, Fourth Military \\ Medical University, Xi'an, \\ People's Republic of China; \\ ${ }^{3}$ Department of Digestive \\ Interventional Radiology, Xijing \\ Hospital, Fourth Military Medical \\ University, Xi'an, People's Republic \\ of China; ${ }^{4}$ Department of Biomedical \\ Engineering, Northwestern University, \\ Chicago, IL, USA; ${ }^{5}$ Robert H Lurie \\ Comprehensive Cancer Center. \\ Chicago, IL, USA
}

Correspondence: Andrew C Larson Departments of Radiology and Biomedical Engineering, Northwestern University Feinberg School of Medicine, 737 N Michigan Ave, 16th Floor,

Chicago, IL 606 I I, USA

Tel + I 3129263499

Fax + I $312926599 \mid$

Email a-larson@northwestern.edu
Purpose: Photothermal ablation is a minimally invasive approach, which typically involves delivery of photothermal sensitizers to targeted tissues. The purpose of our study was to demonstrate that gold nanoparticles are phagocytosed by pancreatic cancer cells, thus permitting magnetic resonance imaging (MRI) of sensitizer delivery and photothermal ablation.

Patients and methods: Iron-oxide core/gold-shell nanoparticles (GoldMag ${ }^{\circledR}, 30 \mathrm{~nm}$ diameter; Xi' an GoldMag Biotechnology Co, Xi'an, People's Republic of China) were used. In a 96-well plate, $3 \times 10^{4}$ PANC-1 (human pancreatic cancer cell line) cells were placed. GoldMag $(0,25$, or $50 \mu \mathrm{g} / \mathrm{mL}$ ) was added to each well and 24 hours allowed for cellular uptake. Samples were then divided into two groups: one treated with photothermal ablation $\left(7.9 \mathrm{~W} / \mathrm{cm}^{2}\right)$ for 5 minutes, the other not treated. Photothermal ablation was performed using laser system (BWF5; B\&W Tek, Inc, Newark, DE, USA). Intraprocedural temperature changes were measured using a fiber optic temperature probe (FTP-LN2; Photon Control Inc, Burnaby, BC, Canada). After 24 hours, the remaining number of viable cells was counted using trypan blue staining; cell proliferation percentage was calculated based on the total number of viable cells after treatment compared with control. MRI of GoldMag uptake was performed using a 7.0T ClinScan system (Bruker BioSpin, Ettlingen, Germany).

Results: Temperature curves demonstrated that with increased GoldMag uptake, laser irradiation produced higher temperature elevations in the corresponding samples; temperature elevations of $12.89^{\circ} \mathrm{C}, 35.16^{\circ} \mathrm{C}$, and $79.51^{\circ} \mathrm{C}$ were achieved for 0,25 , and $50 \mu \mathrm{g} / \mathrm{mL}$ GoldMag. Without photothermal ablation, the cell proliferation percentage changed from $100 \%$ to $71.3 \%$ and $47.0 \%$ for cells treated with 25 and $50 \mu \mathrm{g} / \mathrm{mL}$ GoldMag. Photothermal ablation of PANC- 1 cells demonstrated an effective treatment response, specifically a reduction to only $61 \%, 21.9 \%$, and $2.3 \%$ cell proliferation for cells treated with 0,25 , and $50 \mu \mathrm{g} / \mathrm{mL}$ GoldMag. MRI was able to visualize GoldMag uptake within PANC-1 cells.

Conclusion: Our findings suggest that photothermal ablation may be effective in the treatment of pancreatic cancer. GoldMag nanoparticles could serve as photothermal sensitizers, and MRI is feasible to quantify delivery.

Keywords: photothermal ablation therapy, hybrid nanoparticles, magnetic resonance imaging

\section{Introduction}

Pancreatic cancer is the fourth leading cause of cancer mortality in the United States with an overall 5-year survival rate less than 5\%. ${ }^{1,2}$ Although surgical resection is the sole curative treatment for pancreatic cancer, only 5\%-15\% of patients with pancreatic cancer are amenable for surgery at the time of diagnosis. Even with an optimal curative resection, the median survival for pancreatic cancer patients is approximately 
2 years, with a 5 -year survival of $15 \%-20 \%$, and for those with metastatic disease, survival is shorter than 6 months..$^{3-5}$ Disruptive approaches are critically needed to impact this deadly disease, and photothermal ablation therapy is one such emerging treatment modality.

Photothermal ablation is a minimally invasive therapy that typically involves the application of photothermal sensitizers. ${ }^{6}$ These photothermal sensitizers transform the absorbed light (typically laser irradiation) into heat, thus increasing temperatures within the local vicinity of these sensitizing agents. When tissues are heated above $42^{\circ} \mathrm{C}$, irreversible cellular damage can occur, eventually resulting in cell death. ${ }^{7}$ Long-wavelength $(800-1300 \mathrm{~nm}$ ) laser irradiation is necessary for the penetration of tissues during in vivo photothermal ablation procedures; thus, for these applications, the absorption band for nanoparticle sensitizers must be in the nearinfrared (NIR) region. ${ }^{8}$ NIR resonant nanomaterials such as gold nanorods, carbon tubes, and multifunctional magnetic gold nanoshells have each demonstrated the potential to serve as sensitizers during photothermal ablation. ${ }^{6,910}$ Gold nanoparticles permit targeted heat deposition due to their strong absorption cross section and light-to-heat conversion characteristics. ${ }^{11}$ To enhance tumor-specific heating and thermal deposition, a number of researchers have explored the potential of multifunctional gold nanomaterials; these have been proven as effective photothermal sensitizers for NIR laser irradiation. ${ }^{6,9,12,13}$

In vivo approaches for noninvasive quantification of gold nanoparticle delivery may be critically needed to optimize these laser irradiation procedures. Super-paramagnetic iron oxide and/or ultra-small superparamagnetic iron oxide nanoparticles have been used to label cells, microcapsules, and embolic particles for in vivo tracking with magnetic resonance imaging (MRI) following systemic administration. ${ }^{14-17}$ Magnetic susceptibility differences between the iron oxide particles and surrounding tissues leads to local magnetic field gradients with proportional signal losses via R2 and $\mathrm{R} 2 *$ relaxation mechanisms. Thus, the quantification of R2 and $\mathrm{R} 2 *$ can be used to estimate intratumoral concentrations and the biodistribution of particles containing iron-oxide nanoparticles. ${ }^{18}$

In current study, we investigated the use of gold shelliron oxide core hybrid nanoparticles $\left(\mathrm{Fe}_{3} \mathrm{O}_{4} / \mathrm{Au}\right)$ for both imaging and laser irradiation. The aim of our study was to demonstrate that these hybrid nanoparticles are phagocytosed by pancreatic cancer cells, permit quantitative MRI, and elicit a photothermal response with NIR laser irradiation.

\section{Material and methods Hybrid iron oxide core gold-shell nanoparticles}

Hybrid iron oxide core gold-shell nanoparticles (GoldMag ${ }^{\circledR}$, Xi' an GoldMag Biotechnology Co, Xi' an, People's Republic of China) were purchased and used as the photosensitizing agent for the current study. ${ }^{19,20}$ Briefly, the composite particle was prepared by the reduction of $\mathrm{Au}^{3+}$ with hydroxylamine in the presence of $\mathrm{Fe}_{3} \mathrm{O}_{4}$ particles as seeds. First, the seeds were co-precipitated Fe (II) and Fe (III) ions in alkaline medium, followed by rinsing with water several times until the $\mathrm{pH}$ reached 6-7. Second, $\mathrm{Fe}_{3} \mathrm{O}_{4}$ particles were dispersed in $0.1 \mathrm{~mol} / \mathrm{L} \mathrm{HAuCl}_{4} \cdot 4 \mathrm{H}_{2} \mathrm{O}$ solution in a beaker, and slowly mixed in a shaking incubator to allow adsorption of $\mathrm{Au}^{3+}$ onto the $\mathrm{Fe}_{3} \mathrm{O}_{4}$ surface. $\mathrm{NH}_{2} \mathrm{OH}$ solution of $80 \mathrm{mmol} / \mathrm{L}$ was then added to the system. The mixture was incubated with shaking for 1 hour. The core/shell structure of $\mathrm{Fe}_{3} \mathrm{O}_{4} / \mathrm{Au}$ was formed and then washed with $1 \mathrm{M} \mathrm{HCl}$ solution. Finally, the particles were washed with water until the $\mathrm{pH}$ was 6.7.

Transmission electron microscopy (TEM) images of these GoldMag nanoparticles were digitized with a high-magnification (FEI Tecnai Spirit G2; FEI Company, Hillsboro, OR, USA). Absorption spectra of the GoldMag nanoparticles $\left(\mathrm{Fe}_{3} \mathrm{O}_{4} / \mathrm{Au}\right.$ core/shell nanoparticles) were measured and compared with bare $\mathrm{Fe}_{3} \mathrm{O}_{4}$ nanoparticles.

\section{Cell culture}

A human pancreatic cancer cell line (PANC-1) was purchased from American Type Culture Collection (ATCC, Manassas, VA, USA) and cultured using DMEM (Dulbecco's Modified Eagle's Medium; Life Technologies, Carlsbad, CA, USA) with 10\% fetal bovine serum (Gemini Bio-Products, West Sacramento, CA, USA) and 1\% Pen-Strep (Sigma-Aldrich, St Louis, MO, USA). Cells were maintained in culture flasks at $37^{\circ} \mathrm{C}$ in a humidified atmosphere containing $5 \% \mathrm{CO}_{2}$. The viability of the cells was evaluated with trypan blue staining (confirming $>90 \%$ cell viability when plating the cells).

\section{Temperature measurements}

Representative samples with $0 \mu \mathrm{g} / \mathrm{mL}, 25 \mu \mathrm{g} / \mathrm{mL}$, and $50 \mu \mathrm{g} / \mathrm{mL}$ of the GoldMag nanoparticles in $200 \mu \mathrm{L}$ DMEM culture medium were plated in a 96-well cell culture plate (well bottom area $=0.32 \mathrm{~cm}^{2}$ ). Samples were irradiated using an NIR laser system (BWF5; B\&W Tek, Inc, Newark, DE, USA) with diode fiber laser and continuous wave at wavelength of $808 \mathrm{~nm}$; four separate samples for each nanoparticle concentration were irradiated with 
power densities $=3.2 \mathrm{~W} / \mathrm{cm}^{2}(1.0 \mathrm{~W}), 4.7 \mathrm{~W} / \mathrm{cm}^{2}(1.5 \mathrm{~W})$, $6.3 \mathrm{~W} / \mathrm{cm}^{2}(2.0 \mathrm{~W})$, and $7.9 \mathrm{~W} / \mathrm{cm}^{2}(2.5 \mathrm{~W})$, respectively. The intraprocedural temperature changes were recorded using a fiber optic temperature probe (FTP-LN2; Photon Control Inc, Burnaby, BC, Canada) with measurements recorded at 15 -second intervals. The fiber probe was vertically placed in the center of each sample, approximately $3-5 \mathrm{~mm}$ deep inside the culture media. Baseline temperature was recorded for first 30 seconds before application of the NIR laser irradiation; each sample was then irradiated for 5 minutes and temperature curve plotted.

\section{Cellular uptake of nanoparticles}

TEM (FEI Tecnai Spirit G2) was performed to evaluate the cellular uptake of nanoparticles. Three samples of PANC-1 pancreatic cancer cells were treated with nanoparticles at concentrations of 0,25 , and $50 \mu \mathrm{g} / \mathrm{mL}$, respectively. After allowing 24 hours incubation in complete culture media at $37^{\circ} \mathrm{C}$, the cells were washed three times with phosphatebuffered saline to remove free particles in the medium and rapidly placed into glutaraldehyde and fixed for at least 1 hour at room temperature. The cell samples were then placed in osmium tetroxide, embedded in agar, and processed. The samples were dehydrated in graded concentrations of ethanol and propylene oxide, and embedded in Spurr's plastic. Semi-thin $(5 \mu \mathrm{m})$ sections were cut from blocks, and the blocks were selected for thinning with thin sections $(1.5 \mu \mathrm{m})$ cut and placed on copper grids. Each sample was digitized to visualize the subcellular location of the nanoparticles within the PANC-1 cells.

\section{MRI after nanoparticle uptake}

To evaluate the MRI properties of these hybrid nanoparticles macroscopically after cellular uptake, first we constructed three phantoms, each containing $10 \times 10^{6} \mathrm{PANC}-1$ pancreatic cancer cells. These cells were exposed to 0,25 , and $50 \mu \mathrm{g} /$ $\mathrm{mL}$ dose of nanoparticles for 24 hours, respectively. After washing the cells three times using phosphate-buffered saline, the pancreatic cancer cells were gently mixed with $10 \mathrm{~mL}$ of $0.8 \%$ agarose and placed within $15 \mathrm{~mL}$ centrifuge tubes. MRI studies were performed using a 7.0T ClinScan MRI scanner (Bruker BioSpin, Ettlingen, Germany) with Siemens gradient system/pulse sequences and a surface coil. Quantitative R2 measurements were performed using a Carr-PurcellMeiboom-Gill sequence with the following parameters: repetition time $(\mathrm{TR})=800 \mathrm{~ms}$, echo time $(\mathrm{TE})=11.5,23$, 34.5 , and $46 \mathrm{~ms}$, slice thickness $=0.9 \mathrm{~mm}, 10$ slices, field of view $(\mathrm{FOV})=20 \mathrm{~mm} \times 35 \mathrm{~mm}$, matrix $=114 \times 192$, and bandwidth $=150 \mathrm{~Hz} /$ pixel. $\mathrm{R} 2 *$ was measured using a multiple gradient-recalled echo sequence with the following parameters: $\mathrm{TR}=700 \mathrm{~ms}, \mathrm{TE}=2.47,6.66,9.65$, and $13.24 \mathrm{~ms}$, slice thickness $=0.9 \mathrm{~mm}, 10$ slices, FOV $=20 \mathrm{~mm} \times 35 \mathrm{~mm}$, matrix $=114 \times 192$, and bandwidth $=500 \mathrm{~Hz} /$ pixel. MRI postprocessing was performed offline using Matlab software (The Math Works Inc, Natick, MA, USA). R2 and R2* maps were calculated on a voxel-wise basis employing the nonlinear Levenberg-Marquardt algorithm to fit a mono-exponential function $\mathrm{S}(\mathrm{TEi})=\mathrm{S}(0) \cdot \exp (-\mathrm{R} 2 *$. TEi) . A region of interest (ROI) was manually drawn within each resulting $\mathrm{R} 2$ and $\mathrm{R} 2 *$ map to record the mean $\mathrm{R} 2$ and $\mathrm{R} 2 *$ values within these ROI for each slice within each phantom.

To demonstrate the potential to visualize single cells after nanoparticle uptake, high-resolution three-dimensional multiple gradient-recalled echo scans were performed with the following parameters: $\mathrm{TR}=80 \mathrm{~ms}, \mathrm{TE}=3.22,6.81,10.4$, and $13.99 \mathrm{~ms}$, slice thickness $=0.15 \mathrm{~mm}, \mathrm{FOV}=29 \mathrm{~mm} \times 29 \mathrm{~mm}$, matrix $=384 \times 384$, and bandwidth $=305 \mathrm{~Hz} /$ pixel. PANC- 1 pancreatic cancer cells treated with $25 \mu \mathrm{g} / \mathrm{mL}$ nanoparticles for 24 hours were prepared in an MRI compatible dish (diameter $=1$ inch). After placing these PANC-1 cells at the bottom of the dish, a thin film of agarose was added atop the cells. MRI images were collected using a surface coil with the diameter of $3 \mathrm{~cm}$.

\section{Photothermal ablation}

In a 96-well plate, $3 \times 10^{4}$ PANC-1 cells were placed in each well and exposed to a 0,25 , or $50 \mu \mathrm{g} / \mathrm{mL}$ dose of nanoparticles. After allowing 24 hours for cellular uptake, the samples exposed to these three different nanoparticle concentrations were divided into two groups, one exposed to laser irradiation at a power density of $7.9 \mathrm{~W} / \mathrm{cm}^{2}(2.5 \mathrm{~W} /$ well $)$ for 5 minutes, the other group left untreated thus serving as controls. After exposure, the cells were returned to a $37^{\circ} \mathrm{C}$ incubator for another 24 hours before cell viability tests. These tests were performed in triplicate.

Next, we investigated the efficacy of this photothermal approach when using different power densities during irradiation. Twenty-four hours after PANC-1 cells were exposed to a $25 \mu \mathrm{g} / \mathrm{mL}$ solution of nanoparticles, the cells were irradiated with power densities of $3.2 \mathrm{~W} / \mathrm{cm}^{2}(1.0 \mathrm{~W})$, $4.7 \mathrm{~W} / \mathrm{cm}^{2}(1.5 \mathrm{~W}), 6.3 \mathrm{~W} / \mathrm{cm}^{2}(2.0 \mathrm{~W})$, or $7.9 \mathrm{~W} / \mathrm{cm}^{2}$ $(2.5 \mathrm{~W})$, respectively, for 5 minutes. After these NIR laser procedures, the PANC-1 cells were incubated for another 24 hours before cell viability tests. 
To evaluate the cell proliferation percentage for each of the aforementioned samples, cells were stained using trypan blue, and the total viable cells were counted three times using an automated cell counter (Countess; Invitrogen, San Diego, CA, USA). The cell proliferation percentage was calculated based on the total viable PANC-1 cells after treatment compared with the control group. Each sample was counted in triplicate.

\section{Statistical analysis}

All statistics were performed using the SPSS statistical software package (SPSS, Chicago, IL, USA), version 17. $\mathrm{R} 2$ and R2* values for three groups (control, $25 \mu \mathrm{g} / \mathrm{mL}$, and $50 \mu \mathrm{g} / \mathrm{mL}$ ) were compared by one-way analysis of variance test followed by post hoc tests. Paired $t$-test was performed to compare the cell proliferation between non-ablated cells (GoldMag treated without laser irradiation) and ablated cells (GoldMag treated with laser irradiation) for each GoldMag concentration. Test was considered statistically significant with a $P$-value $<0.05$.

\section{Results}

\section{Heating properties of hybrid nanoparticles}

Representative TEM image for GoldMag nanoparticles is shown in Figure 1A, and absorption spectra of GoldMag nanoparticles $\left(\mathrm{Fe}_{3} \mathrm{O}_{4} / \mathrm{Au}\right.$ core/shell nanoparticles) and bare $\mathrm{Fe}_{3} \mathrm{O}_{4}$ nanoparticles is shown in Figure 1B. A surface plasmon resonance band was observed at $590 \mathrm{~nm}$ for the GoldMag nanoparticles. The surface plasmon resonance band for the $\mathrm{Fe}_{3} \mathrm{O}_{4} / \mathrm{Au}$ core/shell bimetallic nanoparticles showed a red-shift and broadening of the peak, which is commonly observed in other Au bimetallic systems. ${ }^{21,22}$ When we utilized an $808 \mathrm{~nm}$ laser, a corresponding absorption value at $808 \mathrm{~nm}$ for the $\mathrm{Fe}_{3} \mathrm{O}_{4} / \mathrm{Au}$ core/shell nanoparticles was directly converted to heat energy that resulted in our heating profiles (Figure 2). However, bare $\mathrm{Fe}_{3} \mathrm{O}_{4}$ nanoparticles did not show absorption peaks around $808 \mathrm{~nm}$, and no heating resulted following $808 \mathrm{~nm}$ laser irradiation.

For identical laser irradiation power densities of $7.9 \mathrm{~W} / \mathrm{cm}^{2}$, samples containing nanoparticles achieved significantly higher temperatures compared with those samples without the nanoparticles. With an increased concentration of nanoparticles, laser irradiation produced increasingly higher temperature elevations to $13^{\circ} \mathrm{C}, 35^{\circ} \mathrm{C}$, and $80^{\circ} \mathrm{C}$, respectively, at concentrations of 0,25 , and $50 \mu \mathrm{g} / \mathrm{mL}$ nanoparticles. For an identical nanoparticle concentration of $25 \mu \mathrm{g} / \mathrm{mL}$, increasing irradiation power density increased the magnitude of the resulting temperature elevations from $7^{\circ} \mathrm{C}$ at a power density of $3.2 \mathrm{~W} / \mathrm{cm}^{2}$ to $14^{\circ} \mathrm{C}, 26^{\circ} \mathrm{C}$, and $35^{\circ} \mathrm{C}$ for power densities of $4.7,6.3$, and $7.9 \mathrm{~W} / \mathrm{cm}^{2}$, respectively. Dynamic temperature curves during laser irradiation for each concentration and power density are shown in Figure 2.

\section{Cellular uptake}

TEM images showing cellular uptake of nanoparticles after a 24-hour exposure period are shown in Figure 3. These TEM images demonstrated that the particles were phagocytosed into the pancreatic cancer cells (arrow). Nanoparticle uptake increased within the $50 \mu \mathrm{g} / \mathrm{mL}$ exposure group (more nanoparticles observed within $50 \mu \mathrm{g} / \mathrm{mL}$ exposure group sample compared with both $25 \mu \mathrm{g} / \mathrm{mL}$ exposure group and controls).
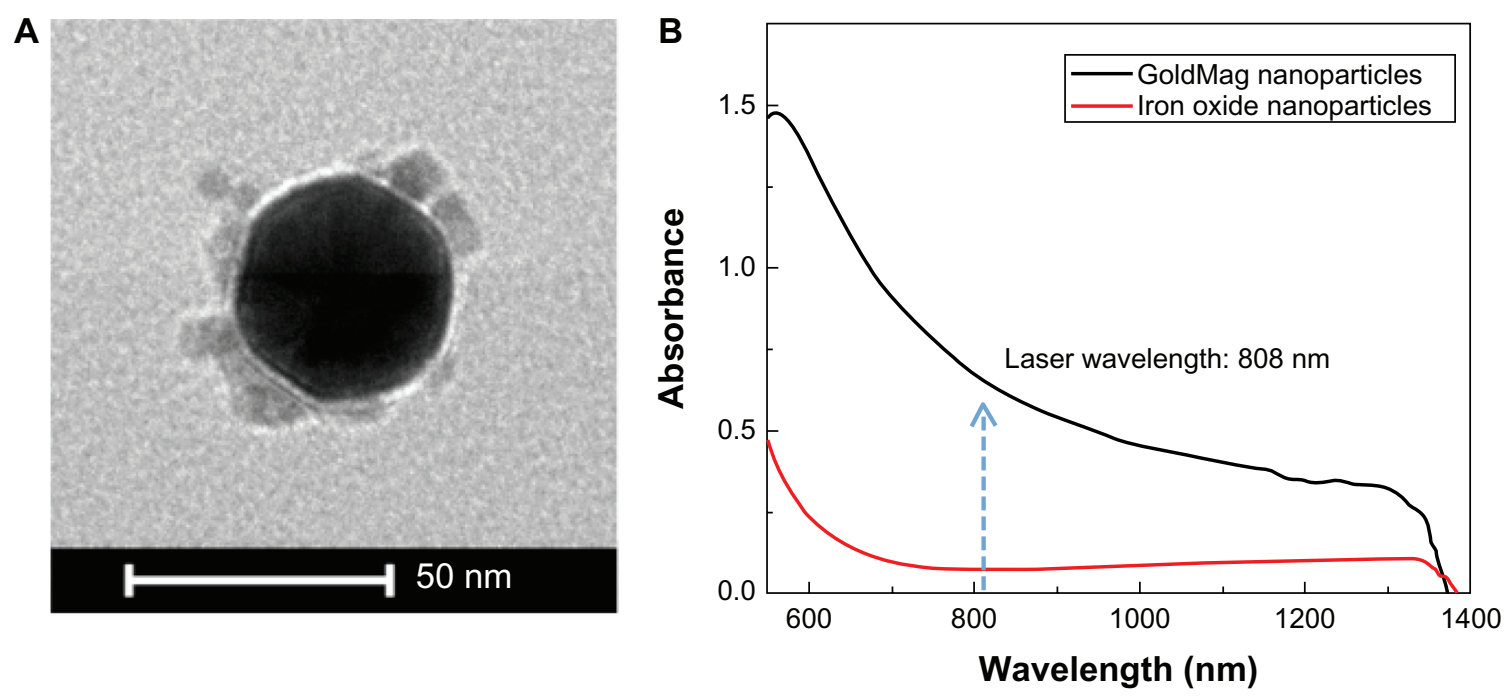

Figure I Transmission electron microscopy image of GoldMag nanoparticles (A), and ultraviolet-visible spectra of $\mathrm{GoldMag}\left(\mathrm{Fe} \mathrm{O}_{4} / \mathrm{Au}\right.$ core/shell nanoparticles) and $\mathrm{Fe} \mathrm{O}_{4}$ in water (arrow) a wavelength of the laser (B). 
A

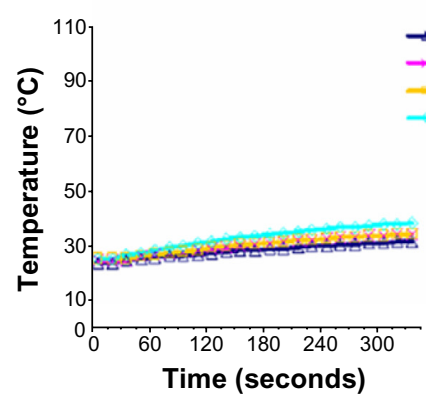

B

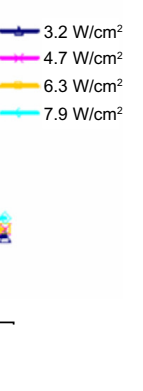

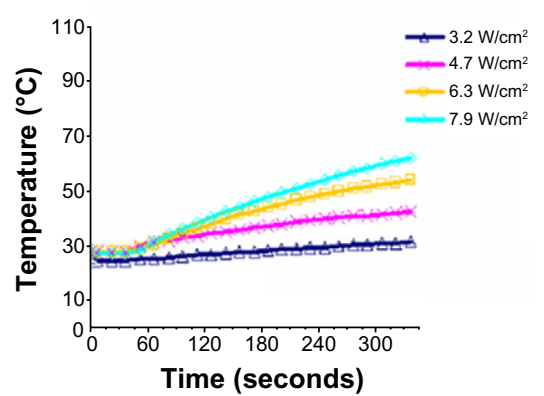

C

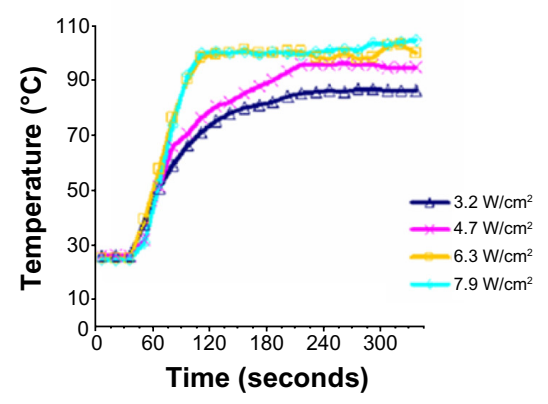

Figure 2 Photothermal response of $0(\mathbf{A}), 25(\mathbf{B})$, and $50(\mathbf{C}) \mu \mathrm{g} / \mathrm{mL}$ nanoparticle samples at 3.2, 4.7, 6.3, and $7.9 \mathrm{~W} / \mathrm{cm}^{2}$ laser irradiation power densities.

\section{MRI measurements}

Voxel-wise R2 and R2* maps for cell suspension phantoms are shown in Figure 4A. Mean R2 and R2* for these cell suspension phantoms increased significantly for those samples exposed to a higher concentration of nanoparticles $(P=0.000$ for R2, and $P=0.000$ for R2*). A difference in mean R2 and $\mathrm{R} 2 *$ values were found between each of the three phantoms. For control sample, mean R2 \pm standard deviation $(\mathrm{SD})=4.77 \pm 1.02\left(\mathrm{~ms}^{-1}\right)$, mean $\mathrm{R} 2 * \pm \mathrm{SD}=9.71 \pm 0.06\left(\mathrm{~ms}^{-1}\right)$; for those cells exposed to $25 \mu \mathrm{g} / \mathrm{mL}$ nanoparticle dose, mean $\mathrm{R} 2 \pm \mathrm{SD}=7.68 \pm 1.75\left(\mathrm{~ms}^{-1}\right)$, mean $\mathrm{R} 2 * \pm \mathrm{SD}=104.25 \pm$ $1.83\left(\mathrm{~ms}^{-1}\right)$; and for cells exposed to $50 \mu \mathrm{g} / \mathrm{mL}$ nanoparticle dose, mean $\mathrm{R} 2 \pm \mathrm{SD}=13.03 \pm 0.64\left(\mathrm{~ms}^{-1}\right)$, mean $\mathrm{R} 2 * \pm$ $\mathrm{SD}=200.86 \pm 4.75\left(\mathrm{~ms}^{-1}\right)$ (Figure 4B).

High-resolution $\mathrm{T} 2 *$-weighted images permitted depiction of individual PANC-1 cell positions after uptake of the iron oxide core gold-shell nanoparticles (after 24 hour exposure period). A representative $\mathrm{T} 2 *$-weighted image is shown in Figure 5 along with corresponding microscopy confirmation image.

\section{Photothermal response}

Representative microscopy images showing the PANC-1 cells exposed to different concentrations of nanoparticles are
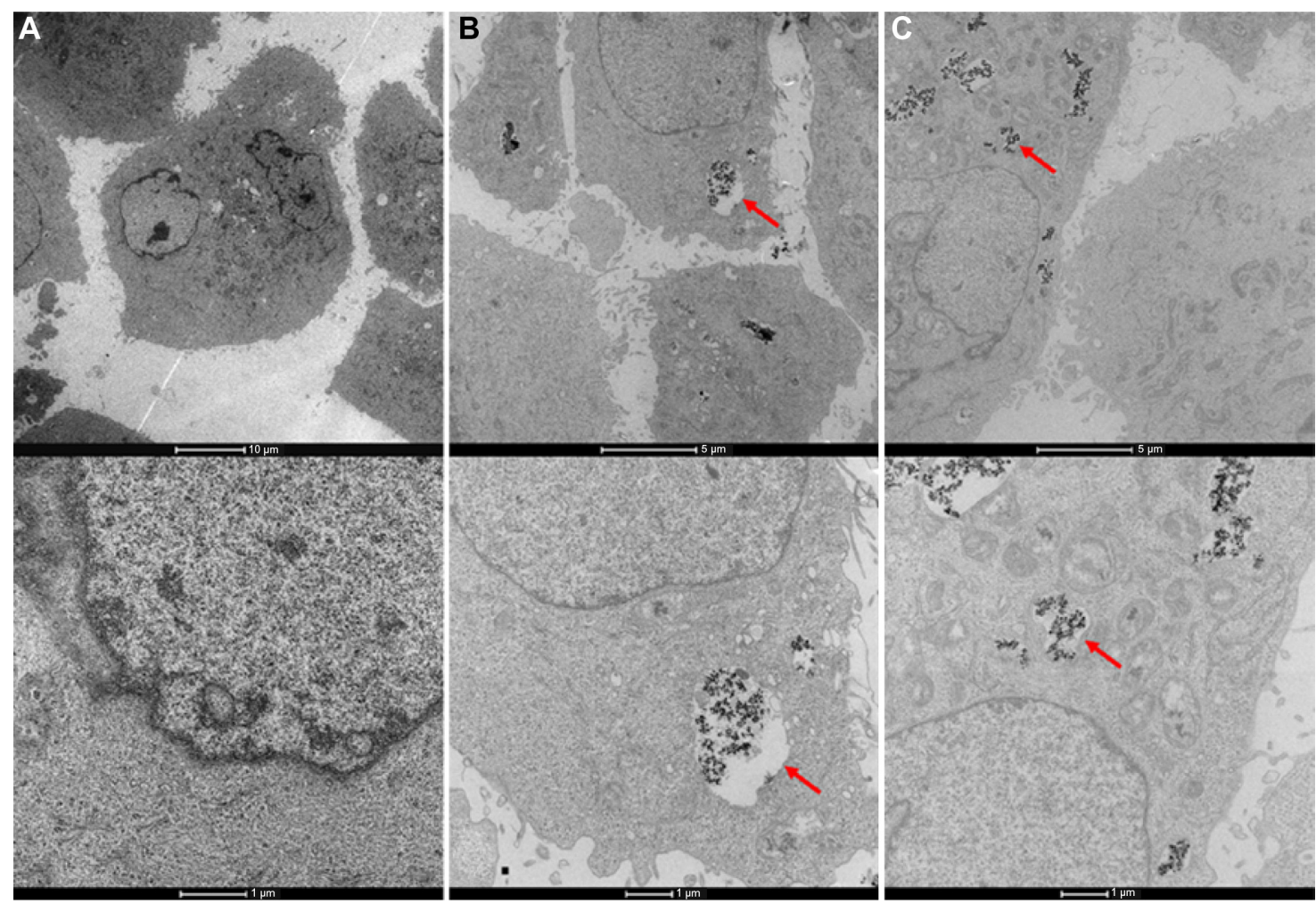

Figure 3 Transmission electron microscopy images of PANC-I cells exposed to 0 (A), 25 (B), and 50 (C) $\mu$ g/mL dose of iron oxide and gold hybrid nanoparticles (arrow). 

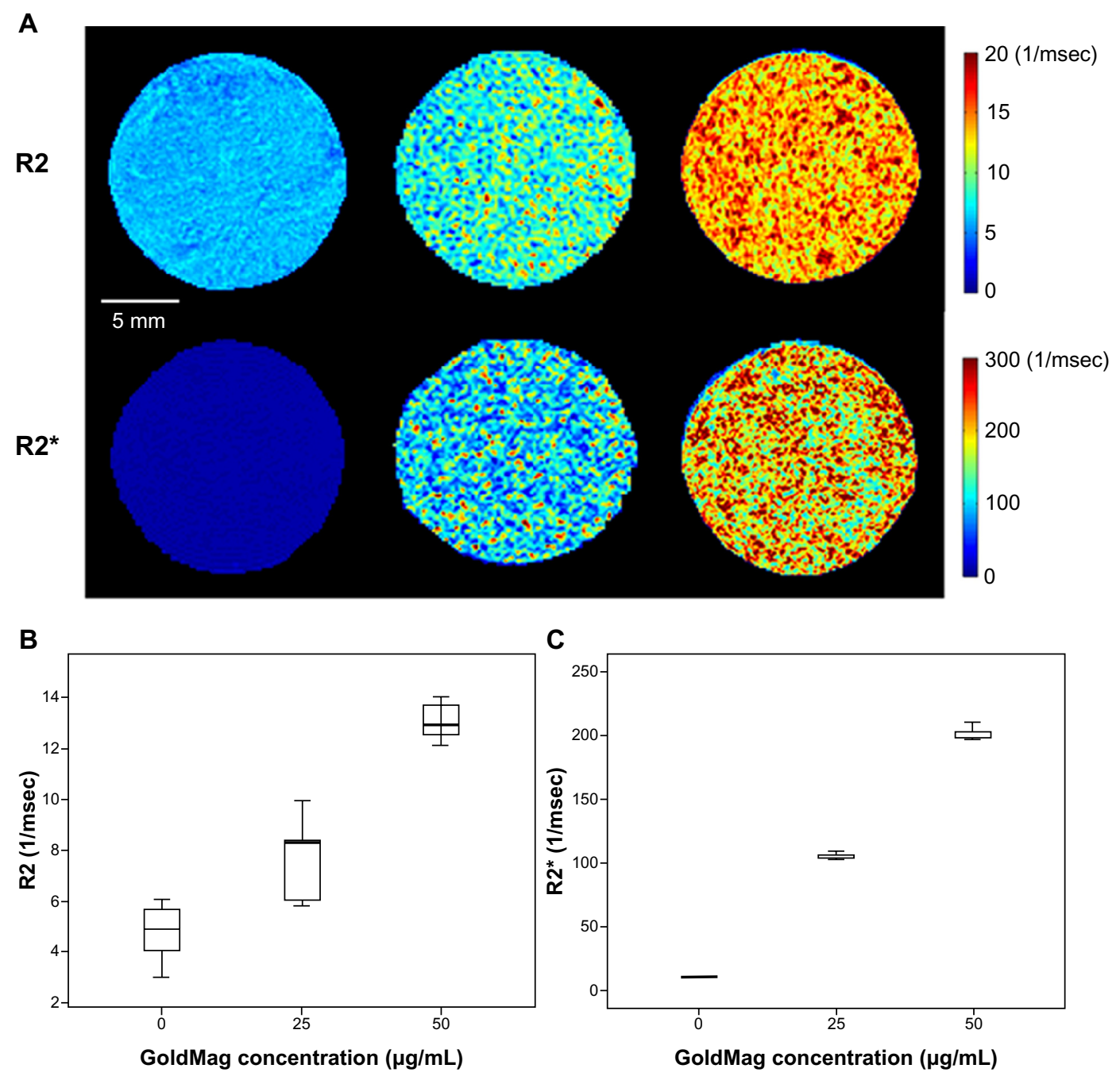

Figure 4 R2 and R2* measurements within PANC-I cell suspensions after 24-hour exposures to nanoparticles at concentrations of 0,25 , and $50 \mu g / m L$ (each cell suspension consisting of $10 \times 10^{6}$ PANC-I cells in $10 \mathrm{~mL} 0.8 \%$ agarose) (A). Mean R2 (B) and R2* values (C) \pm standard deviation for each corresponding cell suspension. Note: R2* $2^{*} 2+\mathrm{R} 2$.

A

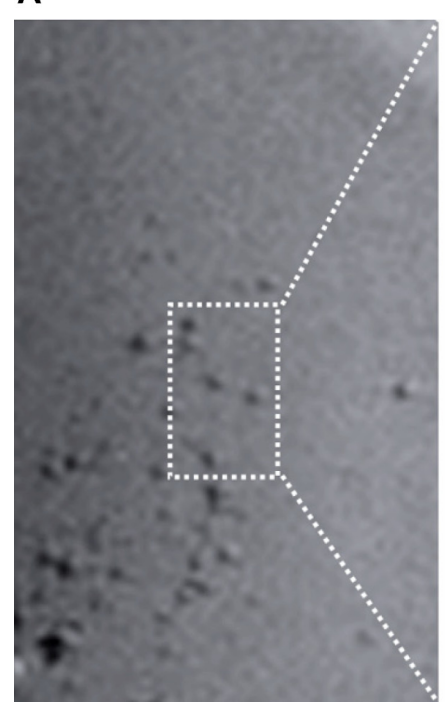

B

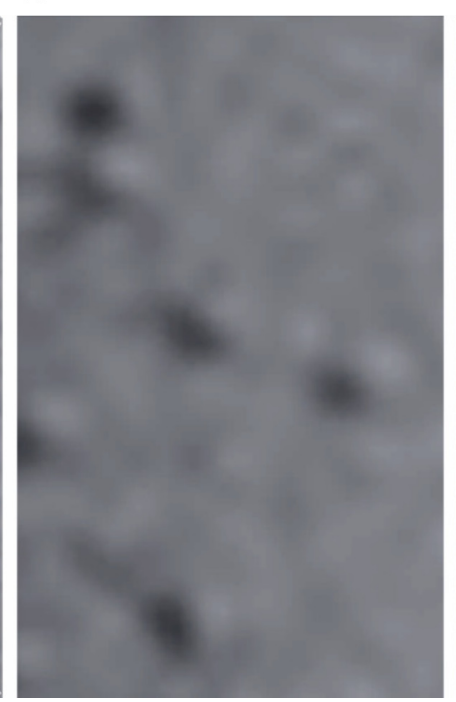

\section{C}

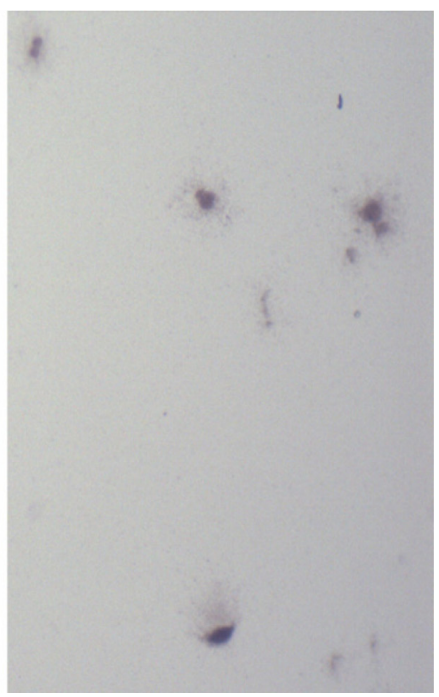

Figure 5 High resolution T2*-weighted images depicting individual PANC-I cell positions after uptake of the iron oxide core gold-shell nanoparticles (A and B); corresponding $\times 20$ microscopy image $(\mathbf{C})$. 
shown in Figure 6. The top row shows the PANC-1 cells exposed to nanoparticles at concentrations of 0,25 , and $50 \mu \mathrm{g} / \mathrm{mL}$ without laser irradiation; without laser irradiation, cell proliferation percentages changed from $100 \%$ to $71.3 \%$ and $47.0 \%$ with exposures to 0,25 , and $50 \mu \mathrm{g} / \mathrm{mL}$ nanoparticle doses, respectively. The bottom row of images shows the pancreatic cancer cell samples treated with gold nanoparticles $(0,25$, and $50 \mu \mathrm{g} / \mathrm{mL}$, respectively) and laser irradiation at a power density of $7.9 \mathrm{~W} / \mathrm{cm}^{2}$; with laser irradiation, the PANC-1 cells showed significantly decreased cell proliferation (compared with corresponding samples without irradiation) to $61 \%, 21.9 \%$, and $2.3 \%$, respectively. The latter results for nanoparticle-exposed PANC-1 cells both with and without laser irradiation are summarized in Figure 7A. Difference was found between non-ablated samples and ablated samples in cell proliferation $(P=0.000$ for each GoldMag concentration).

For PANC-1 cells treated with $25 \mu \mathrm{g} / \mathrm{mL}$ nanoparticles, the photothermal response increased with increasing power density. PANC-1 cell proliferation percentages decreased from $100 \%$ to $75.6 \%, 32.9 \%, 20 \%$, and $21.9 \%$ as power density increased from 3.2 to $4.7,6.3$, and $7.9 \mathrm{~W} / \mathrm{cm}^{2}$, respectively (Figure 7B).

\section{Discussion}

These studies demonstrated the efficacy of using iron oxide core gold-shell nanoparticles as potent MRI-visible photosensitizers during laser irradiation of human pancreatic cancer cells. Previous studies have also shown that other types of nanoparticles can also perform well for these types of applications..$^{23}$ The salient combination of iron oxide core gold-shell nanoparticles with the local application of NIR laser irradiation offers a promising approach for photothermal ablation therapy in the setting of pancreatic cancer. PANC-1 cell proliferation significantly decreased with exposure to increasing concentrations of the nanoparticles and increasing applied power densities. MRI studies demonstrated quantitative increases in both $\mathrm{R} 2$ and $\mathrm{R} 2 *$ with increasing nanoparticle uptake along with the ability to depict individual PANC-1 pancreatic cancer cells after particle phagocytosis.

Heating curves collected during NIR irradiation demonstrated that temperature increased relatively slowly from $8^{\circ} \mathrm{C}$ to $13^{\circ} \mathrm{C}$ for those PANC-1 cells that were not exposed to the iron oxide core gold-shell nanoparticles. Upon 24-hour exposure to these particles, temperature changes during irradiation increased dramatically: $7^{\circ} \mathrm{C}, 14^{\circ} \mathrm{C}, 26^{\circ} \mathrm{C}$, and $35^{\circ} \mathrm{C}$ increases for power densities of 3.2, 4.7, 6.3, and $7.9 \mathrm{~W} / \mathrm{cm}^{2}$, respectively, in $25 \mu \mathrm{g} / \mathrm{mL}$ exposure group; $60^{\circ} \mathrm{C}$, $68^{\circ} \mathrm{C}, 75^{\circ} \mathrm{C}$, and $80^{\circ} \mathrm{C}$ increases for the same power densities in $50 \mu \mathrm{g} / \mathrm{mL}$ exposure group. These hybrid nanoparticles significantly enhanced photothermal response during these NIR laser irradiation procedures. Similar observations have been reported for a number of prior studies using gold nanomaterials as photothermal sensitizers for ablation of human prostate cancer cells, murine renal carcinoma cells, and MDA-MB-435 cells. ${ }^{10,24}$
A

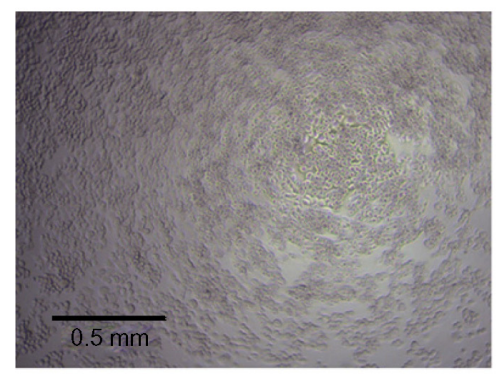

D

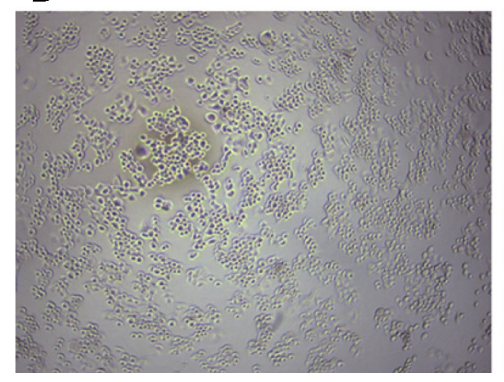

B

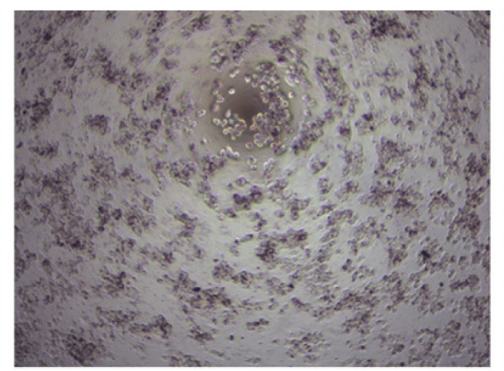

E

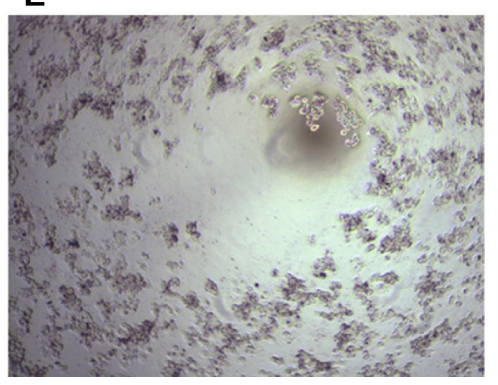

C

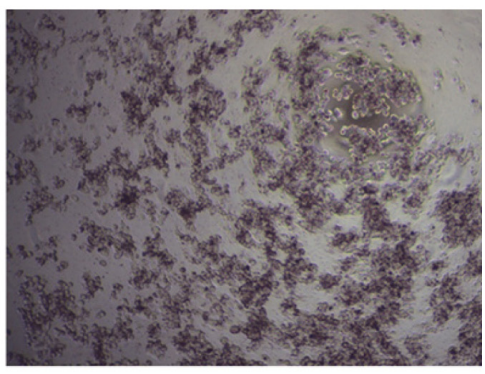

F

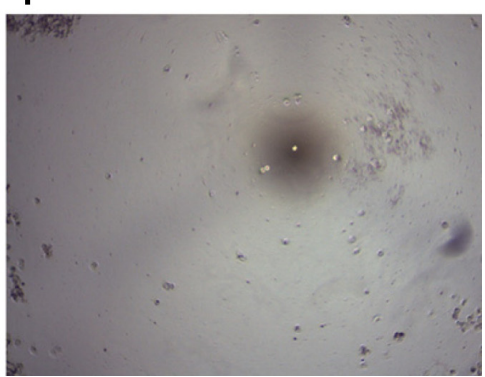

Figure 6 PANC-I cells exposed to 0,25 , and $50 \mu \mathrm{g} / \mathrm{mL}$ dose of nanoparticles, respectively, without laser irradiation $(\mathbf{A}-\mathbf{C})$ and with laser irradiation at $7.9 \mathrm{~W} / \mathrm{cm}^{2}$ power density (D-F). 


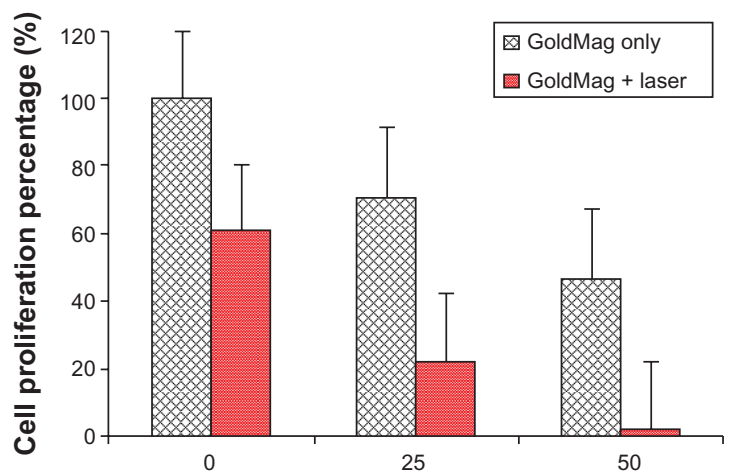

A

GoldMag concentration $(\mu \mathrm{g} / \mathrm{mL})$

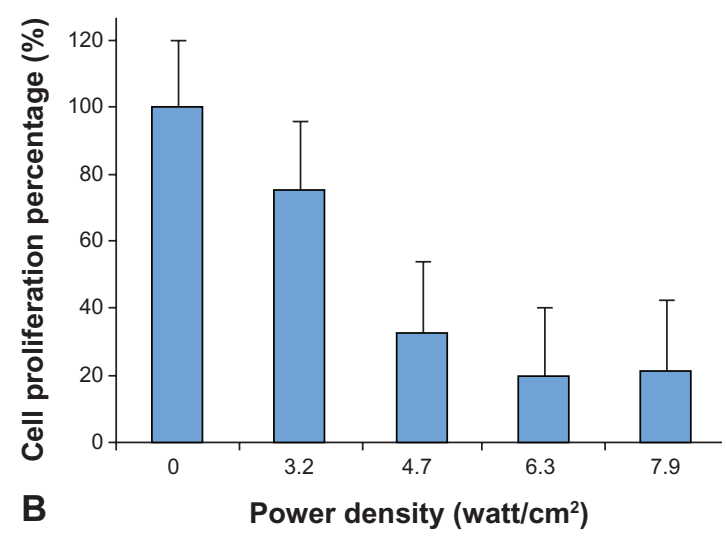

Figure 7 Cell proliferation percentage for PANC-I cells exposed to different concentrations of nanoparticles with (red) and without (grid) laser irradiation (A); cell proliferation percentage for PANC-I cells exposed to $25 \mu \mathrm{g} / \mathrm{mL}$ nanoparticle dose and increasing power densities during NIR laser irradiation (B).

Abbreviation: NIR, near-infrared.

Current clinically used thermal ablation technologies include radiofrequency ablation, ${ }^{25-27}$ microwave coagulation therapy, ${ }^{28}$ and cryoablation therapy. ${ }^{29}$ These thermal ablation approaches have a common limitation, nonspecific heating of targeted tissues, and potential injury to surrounding healthy tissues Photothermal ablation approaches alternatively may permit improved tumor-specific heating with nanomaterials serving to photosensitize the targeted tissues. During the current study, iron oxide core gold-shell nanoparticles were readily phagocytosed into human pancreatic cancer cells. These nanoparticles permitted photothermal ablation in a controllable manner with resulting therapeutic reductions to pancreatic cell proliferation dependent upon the photosensitizer dose and power deposition during irradiation. Given the promising results of these initial in-vitro studies, additional investigations are now warranted to rigorously examine the potential therapeutic efficacy of these approaches with in vivo preclinical animal model studies. These approaches may ultimately overcome some of the limitations of current thermal ablation therapies by limiting unwanted damage to adjacent normal tissues.

Intra-procedural imaging-guidance has been widely advocated for most thermal ablation procedures with current modalities including ultrasound, computed tomography, and MRI. ${ }^{24,30,31} \mathrm{X}$-ray computed tomography, MRI, fluorescence, and optical coherence tomography techniques have each been used to quantitatively visualize gold nanoparticle distributions. ${ }^{6,32-34}$ However, fluorescence and optical imaging typically require cell fixation and staining; while noninvasive in vivo imaging may be feasible for rodent models, depth penetration issues limit application to the examination of only superficial tissues in large mammal and human studies. Given that lack of ionizing radiation, MRI may offer the greatest potential for clinical translation.
Cellular MRI techniques have been widely developed for in vivo visualization and quantification of single cells labeled with iron oxide nanoparticles. ${ }^{35,36}$ Quantitative R2 and R2* measurements can be used to map the biodistribution of iron oxide nanoparticles. ${ }^{35,36}$ The nanoparticles used for the current studies included an iron oxide component as a core of the particles, and subsequent MRI studies demonstrated that increased PANC-1 cell uptake yielded significant changes in both R2 and R2* relaxation. Given the noninvasive nature of these measurements, these can already be readily performed in clinical settings. Such measurements may ultimately be critical for treatment planning, allowing the physicians to potentially adjust laser irradiation parameters (power density and duration) based upon MRI assessments of nanoparticle deposition within the targeted pancreatic tumor tissues. Given the superior soft tissue contrast over competing modalities, MRI may also be ideal for real-time placement of the diode fiber laser probe (akin to current clinical procedures using MRI for the placement of radiofrequency ablation or cryo-probes as well as biopsy needles). ${ }^{37}$

The primary limitation of this current in-vitro feasibility study was the lack of subsequent in vivo validation. This will be a critical next step and will allow important investigation of physiologic influences that may impact therapeutic outcomes. These influences include the resultant nanoparticle biodistribution (following intravenous systemic administration or direction percutaneous injection) as well as potential local heat losses due to perfusion of the tissue targeted for ablation (heat-sink effects). ${ }^{38}$ The circulation times of nanoparticles after intravenous injection has been a challenge for targeted therapy. Particle size and surface charge are critical factors for avoiding uptake by macrophages prior to reaching the targeted tumors. 
Polyethylene glycol can extend circulation times but was not used for surface modification of our nanoparticles for the current study. For future studies, the in vivo bioavailablity of Goldmag nanoparticles should be further investigated. In addition, targeting moieties can be readily added to these nanoparticles to facilitate selective delivery to the targeted tumor tissues. Active targeting such as antibody targeting enhances targeting efficiency and should result in better therapeutic response than passive targeting approaches. Prostate stem cell antigen antibodies have been added to these hybrid iron oxide core gold-shell nanoparticles for selective delivery to prostate tumors. ${ }^{39}$ Anti-epidermal growth factor receptor antibodies are also overexpressed in most human pancreatic cancer cell lines, offering additional potential targets to facilitate selective delivery. ${ }^{6,9}$ The decrease in cell proliferation after nanoparticle administration observed in our study may have resulted from the high surface charge of these nanoparticles. Future modification and improvement of these gold nanoparticles is warranted.

In conclusion, these studies demonstrated the potential to use iron oxide gold-shell nanoparticles as MRI-visible photothermal sensitizers during laser irradiation of pancreatic cancer cells. Exposure to these nanoparticles and subsequent laser irradiation led to significant reductions in pancreatic cancer cell proliferation; MRI R2 and R2* measurements correlated to nanoparticle cellular uptake levels. Future in vivo translational studies are now warranted to validate these approaches in animal models of pancreatic cancer.

\section{Acknowledgments}

This publication was made possible by: Grant number CA141047 and CA159178 from the National Institutes of Health; and Grant 81220108011 from the National Natural Science Foundation of China. Its contents are solely the responsibility of the authors and do not necessarily represent the official view of the National Institutes of Health.

\section{Disclosure}

The authors report no conflicts of interest in this work.

\section{References}

1. Hidalgo M. Pancreatic cancer. N Engl J Med. 2010;362(17):1605-1617.

2. Jemal A, Siegel R, Xu J, Ward E. Cancer statistics, 2010. CA Cancer J Clin. 2010;60(5):277-300.

3. Philip PA, Mooney M, Jaffe D, et al. Consensus report of the national cancer institute clinical trials planning meeting on pancreas cancer treatment. J Clin Oncol. 2009;27(33):5660-5669.
4. Willett CG, Czito BG, Bendell JC, Ryan DP. Locally advanced pancreatic cancer. J Clin Oncol. 2005;23(20):4538-4544.

5. Lebedeva IV, Sarkar D, Su ZZ, et al. Molecular target-based therapy of pancreatic cancer. Cancer Res. 2006;66(4):2403-2413.

6. Park JH, von Maltzahn G, Xu MJ, et al. Cooperative nanomaterial system to sensitize, target, and treat tumors. Proc Natl Acad Sci U SA. 2010;107(3):981-986.

7. Cobley CM, Au L, Chen J, Xia Y. Targeting gold nanocages to cancer cells for photothermal destruction and drug delivery. Expert Opin Drug Deliv. 2010;7(5):577-587.

8. Liu H, Chen D, Tang F, et al. Photothermal therapy of Lewis lung carcinoma in mice using gold nanoshells on carboxylated polystyrene spheres. Nanotechnology. 2008;19(45):455101.

9. Huang X, El-Sayed IH, Qian W, El-Sayed MA. Cancer cell imaging and photothermal therapy in the near-infrared region by using gold nanorods. J Am Chem Soc. 2006;128(6):2115-2120.

10. Fisher JW, Sarkar S, Buchanan CF, et al. Photothermal response of human and murine cancer cells to multiwalled carbon nanotubes after laser irradiation. Cancer Res. 2010;70(23):9855-9864.

11. Huang X, Jain PK, El-Sayed IH, El-Sayed MA. Gold nanoparticles: interesting optical properties and recent applications in cancer diagnostics and therapy. Nanomedicine (Lond). 2007;2(5):681-693.

12. Lu W, Singh AK, Khan SA, Senapati D, Yu H, Ray PC. Gold nanopopcorn-based targeted diagnosis, nanotherapy treatment, and in situ monitoring of photothermal therapy response of prostate cancer cells using surface-enhanced Raman spectroscopy. J Am Chem Soc. 2010;132(51):18103-18114.

13. Morton JG, Day ES, Halas NJ, West JL. Nanoshells for photothermal cancer therapy. Methods Mol Biol. 2010;624:101-117.

14. Leung K. Ultrasmall superparamagnetic iron oxide nanoparticles conjugated with Ile-Pro-Leu-Pro-Phe-Tyr-Asn. Molecular Imaging and Contrast Agent Database (MICAD) [Internet]. Bethesda (MD): National Center for Biotechnology Information (US); 2004-2013. February 23, 2010 [updated March 25, 2010].

15. Liu G, Wang Z, Lu J, et al. Low molecular weight alkyl-polycation wrapped magnetite nanoparticle clusters as MRI probes for stem cell labeling and in vivo imaging. Biomaterials. 2011;32(2):528-537.

16. Kinoshita M, Yoshioka Y, Okita Y, Hashimoto N, Yoshimine T. MR molecular imaging of HER-2 in a murine tumor xenograft by SPIO labeling of anti-HER-2 affibody. Contrast Media Mol Imaging. 2010;5(1):18-22.

17. Islam T, Josephson L. Current state and future applications of active targeting in malignancies using superparamagnetic iron oxide nanoparticles. Cancer Biomark. 2009;5(2):99-107.

18. Persigehl T, Bieker R, Matuszewski L, et al. Antiangiogenic tumor treatment: early noninvasive monitoring with USPIO-enhanced MR imaging in mice. Radiology. 2007;244(2):449-456.

19. Zhang S, Zou L, Zhang D, Pang X, Yang H, Xu Y. GoldMag nanoparticles with core/shell structure: characterization and application in MR molecular imaging. J Nanopart Res. 2011;13:3867-3876.

20. Cui Y, Wang Y, Hui W, Zhang Z, Xin X, Chen C. The synthesis of GoldMag nano-particles and their application for antibody immobilization. Biomed Microdevices. 2005;7(2):153-156.

21. Lyon JL, Fleming DA, Stone MB, Schiffer P, Williams ME. Synthesis of Fe oxide core/Au shell nanoparticles by iterative hydroxylamine seeding. Nano Letters. 2004;4(4):719-723.

22. Cheng G, Walker ARH. Synthesis and characterization of cobalt/gold bimetallic nanoparticles. J Magn Magn Mater. 2007;311:31-35.

23. Ma LL, Feldman MD, Tam JM, et al. Small multifunctional nanoclusters (nanoroses) for targeted cellular imaging and therapy. ACS Nano. 2009;3(9):2686-2696.

24. von Maltzahn G, Park JH, Agrawal A, et al. Computationally guided photothermal tumor therapy using long-circulating gold nanorod antennas. Cancer Res. 2009;69(9):3892-3900.

25. Edrei Y, Gross E, Corchia N, et al. Vascular profile characterization of liver tumors by magnetic resonance imaging using hemodynamic response imaging in mice. Neoplasia. 2011;13(3):244-253. 
26. Lencioni R, Cioni D, Crocetti L, et al. Early-stage hepatocellular carcinoma in patients with cirrhosis: long-term results of percutaneous imageguided radiofrequency ablation. Radiology. 2005;234(3):961-967.

27. Lau WY, Lai EC. The current role of radiofrequency ablation in the management of hepatocellular carcinoma: a systematic review. Ann Surg. 2009;249(1):20-25.

28. Liang P, Dong B, Yu X, et al. Prognostic factors for survival in patients with hepatocellular carcinoma after percutaneous microwave ablation. Radiology. 2005;235(1):299-307.

29. Hinshaw JL, Lee FT Jr. Cryoablation for liver cancer. Tech Vasc Interv Radiol. 2007;10(1):47-57.

30. Hong K, Georgiades CS, Geschwind JF. Technology insight: Imageguided therapies for hepatocellular carcinoma - intra-arterial and ablative techniques. Nat Clin Pract Oncol. 2006;3(6):315-324.

31. Guo Y, Zhang Y, Nijm GM, et al. Irreversible electroporation in the liver: contrast-enhanced inversion-recovery MR imaging approaches to differentiate reversibly electroporated penumbra from irreversibly electroporated ablation zones. Radiology. 2011;258(2):461-468.

32. Kim D, Park S, Lee JH, Jeong YY, Jon S. Antibiofouling polymercoated gold nanoparticles as a contrast agent for in vivo X-ray computed tomography imaging. J Am Chem Soc. 2007;129(24):7661-7665.
33. Yang L, Mao H, Cao Z, et al. Molecular imaging of pancreatic cancer in an animal model using targeted multifunctional nanoparticles. Gastroenterology. 2009;136(5):1514-1525. e2.

34. Zagaynova EV, Shirmanova MV, Kirillin MY, et al. Contrasting properties of gold nanoparticles for optical coherence tomography: phantom, in vivo studies and Monte Carlo simulation. Phys Med Biol. 2008;53(18):4995-5009.

35. Arbab AS, Yocum GT, Kalish H, et al. Efficient magnetic cell labeling with protamine sulfate complexed to ferumoxides for cellular MRI. Blood. 2004;104(4):1217-1223.

36. Wu YL, Ye Q, Foley LM, et al. In situ labeling of immune cells with iron oxide particles: an approach to detect organ rejection by cellular MRI. Proc Natl Acad Sci U S A. 2006;103(6):1852-1857.

37. Mahnken AH, Buecker A, Spuentrup E, et al. MR-guided radiofrequency ablation of hepatic malignancies at $1.5 \mathrm{~T}$ : initial results. J Magn Reson Imaging. 2004;19(3):342-348.

38. Kim SK, Rhim H, Kim YS, et al. Radiofrequency thermal ablation of hepatic tumors: pitfalls and challenges. Abdom Imaging. 2005;30(6): 727-733.

39. Ren J, Zhang Z, Wang F, et al. MRI of prostate stem cell antigen expression in prostate tumors. Nanomedicine (Lond). 2012;7(5):691-703.
International Journal of Nanomedicine

\section{Publish your work in this journal}

The International Journal of Nanomedicine is an international, peerreviewed journal focusing on the application of nanotechnology in diagnostics, therapeutics, and drug delivery systems throughout the biomedical field. This journal is indexed on PubMed Central, MedLine, CAS, SciSearch $\AA$, Current Contents ${ }^{\circledR} /$ Clinical Medicine,

\section{Dovepress}

Journal Citation Reports/Science Edition, EMBase, Scopus and the Elsevier Bibliographic databases. The manuscript management system is completely online and includes a very quick and fair peer-review system, which is all easy to use. Visit http://www.dovepress.com/ testimonials.php to read real quotes from published authors. 